\title{
ESTUDO DE CASO DO CORREDOR ECOLÓGICO E URBANO DO MINDU: MAPEAMENTO DE PASSIVOS AMBIENTAIS DO PARQUE MUNICIPAL DO MINDU, MANAUS-AM
}

\author{
Rogério Fonseca $^{12}$; Lizit Alencar da Costa $^{3}$; Julio César Rodriguez Tello; Carlos Moisés Medeiros ${ }^{4}$
}

\section{RESUMO}

Nas primeiras incursões operacionais e mesmo administrativas no parque municipal do Mindu, percebeu-se que muitos dados eram coletados e arquivados dispersadamente sem que houvesse algum tratamento ou análise criteriosa sobre os mesmos. Com muitos dados dispersos estabeleceu-se um procedimento de lançamento dos mesmos em um sistema único, escolhendo um que desse a oportunidade de gerar e disponibilizar informações geográficas sobre a área, utilizando, portanto, um SIG livre, o SPRING, por possuir um amplo espectro de recepção para o tratamento dos dados para obtenção de informações precisas sobre a unidade de conservação, a custo zero. O presente trabalho objetivou de forma simples e barata, aperfeiçoar os recursos humanos e materiais, para obter um mapeamento preciso dos passivos ambientais que afetavam o parque municipal do Mindu, direcionando as ações das equipes que compõem a gestão desta unidade de conservação, para concentrar os esforços no que é de maior problemática no presente para garantir a perpetuidade do patrimônio natural existente nesta área protegida a longo prazo.

Palavras chave: Geotecnologias, danos ambientais, gestão de riscos.

\section{STUDY OF CASE THE MINDU ECOLOGICAL URBAN CORRIDOR: MAPPING ENVIRONMENTAL LIABILITIES OF THE MUNICIPAL PARK OF THE MINDU, MANAUS-AM.}

\begin{abstract}
In the first operational and exactly administrative incursions in the municipal park of the Mindu, it was perceived that many data were collected and filed exhausting without it had some treatment or multicriteria analysis on the same ones. With many dispersed data, a procedure of launching thouse in only are system was established,. Choosing one that could generate and to make available geographic information on the area, being used therefore a open-GIS, the SPRING, for possessing an ample specter of reception for the treatment of the data for attainment of necessary information on the protected area, cost zero. The present work aimed of simple and cheap form, to optimize the human resources and material, to get a necessary mapping of the ambient liabilities that affected the municipal park of the Mindu, being directed the actions of the teams that they compose the management of this protected area, to concentrate the efforts in what it is of problematic greater in the gift to guarantee the perpetuity of the existing natural patrimony in this protected areas in the long stated period.
\end{abstract}

Keywords: Geotechnologies, environmental liabilities, management of risks

\footnotetext{
${ }^{1}$ Biólogo, Mestre. Faculdade de Ciências Agrárias, Departamento de Ciências Florestais, Universidade Federal do Amazonas, Manaus-AM. rogeriofonseca@ufam.edu.br.

${ }^{2}$ (recebido em 28.07.2011 e aceito para publicação em 15.06.2012)

${ }^{3}$ Engenheiro Florestal, Doutor. Faculdade de Ciências Agrárias, Departamento de Ciências Florestais, Universidade Federal do Amazonas, Manaus-AM. lcosta@ufam.edu.br, jtello@ufam.edu.br.

${ }^{4}$ Agrônomo, Doutor. Faculdade de Ciências Agrárias, Departamento de Ciências Florestais, Universidade Federal do Amazonas, ManausAM.
} 


\section{INTRODUÇÃO}

A espacialização de dados gerados no cotidiano de unidades de conservação (U.C.) trabalhados em ambientes de sistemas de informações geográficas (SIG) faz com que o entendimento de situações até então tidas como naturais, aponte para direções totalmente contrárias às que são imaginadas por alguns gestores de áreas protegidas.

Cada vez mais a gestão baseada em fatos, conciliada à utilização de ferramentas apropriadas, como é o caso de banco de dados geográficos e SIG’s, faz com que se aperfeiçoem as ações de manejo nas unidades de conservação que detêm esta percepção administrativa (Araújo, 2007). O ato simples de se mapear os passivos ambientais gerados em U.C. ou no seu entorno, traz à tona que o monitoramento deve ser premissa básica em qualquer categoria de manejo do sistema de unidades de conservação, pois, na tomada de decisões dará suporte adequado à equipe gestora para direcionar apropriadamente suas ações, não em empirismos ou “feeling” administrativo.

No presente, cada vez mais os órgãos gestores de áreas públicas, devem concentrar esforços na utilização de ferramentas geotecnológicas (GPS, SIG, sensoriamento remoto, aerofotogrametria, etc.) para dar suporte à tomada de decisões, como o trabalho conduzido no Parque Estadual do Bacanga, São Luis - MA, onde a coleta de informações propiciou além da formação de base cartográfica da unidade de conservação novas informações da utilização de recursos no interior de um Parque, PINHEIRO JUNIOR (2006). Também o trabalho de Greggio, et al (2009), em Jaboticabal-SP, onde se mapeou os fragmentos florestais existentes no município, para avaliação quali-quantitativa em escala de espaço e tempo dos mesmos.

Outros dois casos notáveis foram os realizados nos Municípios de Linhares-ES, e de Volta Redonda, onde se utilizou o Sistema de Análise Geo-Ambiental (SAGA) da UFRJ, desenvolvido por Silva (2007), que permitiu aprofundamentos nas condições naturais e antrópicas de ambos os municípios.

Porém, o que se percebe, no geral, é que são poucas as repartições públicas que detêm Know-how e mesmo recursos humanos capacitados para utilização destas ferramentas, e estas que possuem pessoal, utilizam apenas um software estritamente comercial e o mesmo acaba por inviabilizar-se para setores de um mesmo órgão por necessitar da licença de uso.

Uma forma de se livrar das “algemas” impostas pela licença de uso é a utilização de softwares livres (OpenGIS) conciliados a todas as ferramentas geotecnológicas disponíveis, contribuindo para um manejo profissional direcionado à preservação a longo prazo das áreas protegidas públicas e particulares, este estudo demonstra que é possível mapear passivos ambientais numa unidade de conservação urbana que compõem um corredor ecológico como é o caso do Parque Municipal do Mindu, a um custo relativamente baixo, podendo o mesmo ser replicado a outras unidades de conservação.

\section{MATERIAL E MÉTODOS}

A área objeto deste estudo é o Parque Municipal do Mindu, Unidade de Conservação do Grupo de Proteção Integral, localizado no bairro Parque Dez de
Novembro, Zona Centro Sul da cidade de Manaus, Amazonas (Decreto $n^{\circ} .9043$ / 2007) como pode ser visualizado em destaque na Figura 1. 
Figura 1. Área de estudo em relação ao Estado do Amazonas, Município de Manaus e Bacia Hidrográfica do Igarapé do Mindu

Figure 1. Area of study in relation to the State of Amazonas, City of Manaus and hydrographic basin Mindu river

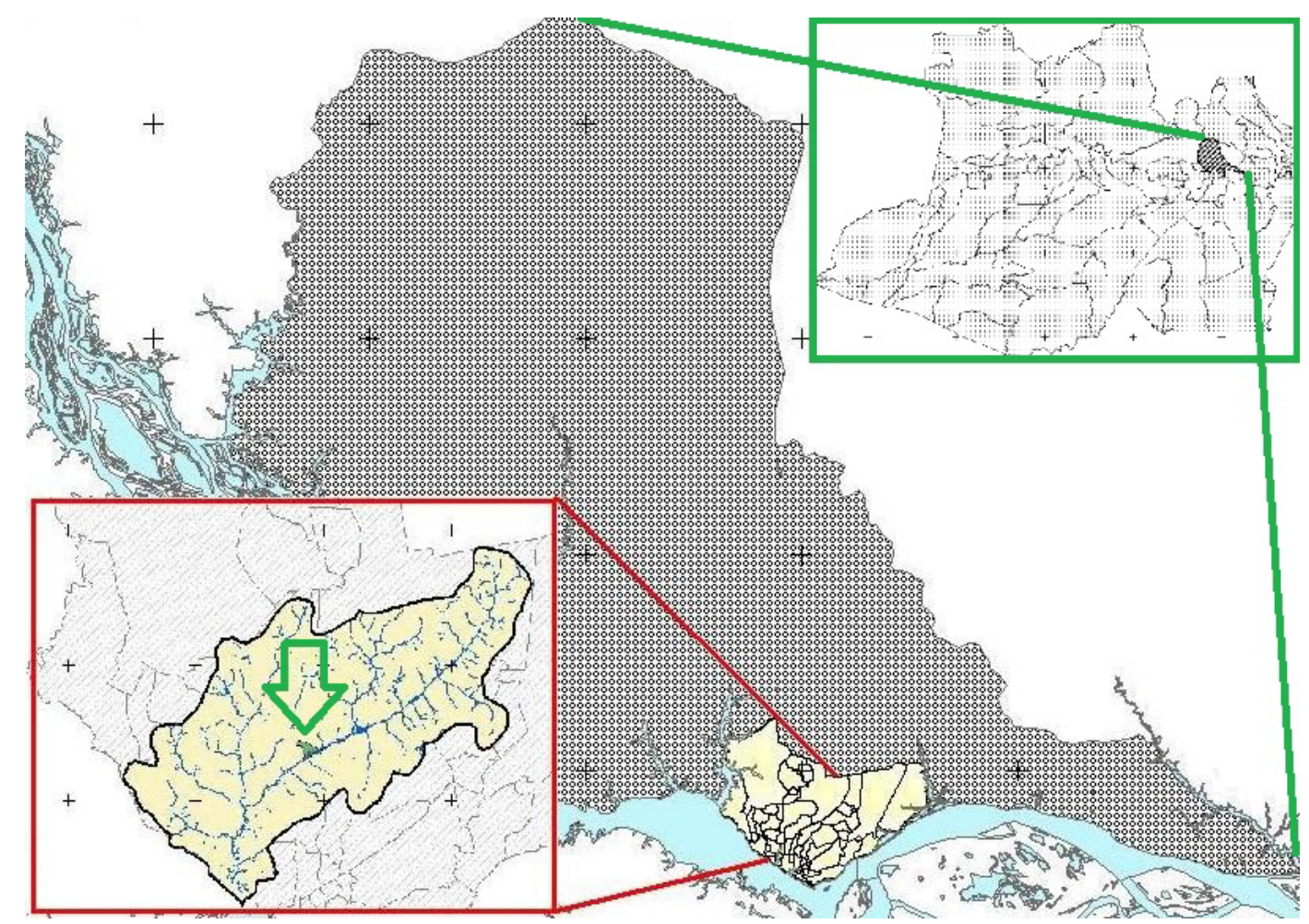

Os materiais utilizados para a elaboração do mapeamento de passivos ambientais foram: livro de registro de ocorrências, autos de infração ambiental e verificação in loco através de aproximadamente 680 expedições de patrulhamento realizadas e registradas pela equipe do Parque do Mindu no período entre dezembro de 2006 à dezembro de 2007 no entorno e limites da unidade de conservação objeto deste estudo.

A fim de registrar visualmente os passivos gerados, criou-se um banco de imagens utilizando uma câmera fotográfica digital e para gerar informações espaciais sobre os passivos utilizou-se um receptor GPS Garminn Map76S, planilha/caderneta de apontamentos de dados de campo. Para a confecção da cartografia analógica, utilizou-se os softwares Track-maker, Scarta e o Spring 4.2.

Os dados coletados para gerar o mapeamento dos passivos ambientais demandou muita atenção, pois remeteu a muitas classes de passivos, como exemplos: incêndios, construções ilegais, quedas de árvores, invasão de limites, lançamento de óleo, lançamento de esgotos, ruídos oriundos de aparelhos sonoros, lançamento de lixo, queima de varrição, coleta ilegal de frutas, etc. Isto por que na análise dos livros de ocorrência bem como dos autos de infração as atividades se embrenhavam a especificação minuciosa do fato ocorrido.

Refinou entre as várias classes, quatro categorias de passivos: 1-Invasão de limites por edificações, entendidas como aquelas obras de construção civil utilizadas como moradias/estabelecimento comercial/terreno cercado que foram estabelecidas nos limites da unidade de conservação e que por motivo diverso teve acréscimo de terreno para o interior da área protegida; 2-Lançamento de resíduos sólidos, líquidos e gasosos, entendidos como todos e quaisquer efluentes que possam interferir de alguma forma à integridade dos recursos naturais inseridos na unidade de conservação; 3Obras no interior e entorno da U.C. sem autorização, 
entendidos como sendo construções diversas não necessariamente para moradia/estabelecimento comercial/terreno cercado; e 4-Catástrofes naturais, que são todos os efeitos gerados por uma ação natural/humana no ecossistema que desencadeou um processo que propiciou algum dano à unidade de conservação ou ao ecossistema próximo da área protegida.
Após definidas as categorias de passivos realizou-se a coleta dos dados geográficos para a espacialização, através de receptor GPS e para formar o banco de imagens, fotografou-se com auxilio de uma câmera digital os passivos encontrados.

\section{RESULTADOS E DISCUSSÂO}

Invasão de limites de U.C. por edificações: no parque do Mindu, constataram-se vinte e três áreas edificadas ultrapassando os limites da região identificada como unidade de conservação. Situações extremamente complexas como a de um posto de combustível dentro dos limites propostos como "unidade de conservação" e outras situações de estranho entendimento como as residências no limite oeste da unidade de conservação.

Todas estas residências acresceram seus terrenos para área interna do parque do Mindu. Contraditoriamente alguns moradores alegaram que a situação dominial destas áreas lhes foram repassadas antes da criação da área protegida objeto deste estudo e que aqueles que prolongaram seus terrenos para a área interna do Parque tiveram autorizações concedidas por políticos que atuavam na região, mas nada documentadamente comprovado.

Comparativamente o estabelecimento de uma unidade de conservação em área rural seja um ato heróico, consolidar diversas opiniões, muitas vezes antagônicas, traz um enorme exercício técnico de sucessivos estudos e consultas públicas que propiciam ou não o estabelecimento da mesma.

Contrariamente às áreas rurais, muitas unidades de conservação urbana são criadas a partir da demanda de moradores e mesmo de pesquisadores, que utilizam determinadas áreas verdes nos limites urbanos de uma cidade para seu lazer, como foi o caso da história de criação do parque do Mindu. Conquistado pela simpatia dos moradores do bairro Parque Dez de Novembro a área em questão foi instituída como protegida, porém, nem tanto pelos vizinhos "de muro" do parque municipal do Mindu.

Quando do estabelecimento da unidade de conservação uma pequena porcentagem dos moradores do entorno imediato tinham em mente qual o objetivo de uma área protegida da categoria parque, ou seja, a criação da área para algum destes não afetaria sua relação com a contínua extração de recursos naturais da área.

Em meados de 2005 foram estabelecidos programas de educação ambiental conduzidos pela Secretaria Municipal de Meio Ambiente e ONG’s locais, a fim de direcionar ações voltadas à conservação da espécie bandeira local, o Sauim-de-Coleira (Saguinus bicolor), o que indiretamente contribuiu com a divulgação da importância das unidades de conservação no meio urbano.

Porém situações de um passado muito recente de sucessivas invasões em várias regiões de Manaus eclodiram um sentimento geral de impunidade fazendo com que alguns moradores de entorno imediato de áreas protegidas de Manaus oportunamente prolongassem seus terrenos para o interior de unidades de conservação já estabelecidas.

Lançamentos de resíduos: identificaram-se em campo todos os pontos de lançamento de efluentes líquidos, sólidos e gasosos, ressaltando que também foi encontrado nos limites da unidade de conservação a emissão de ruídos acima do permitido.

Possuindo um total de 58 pontos de lançamento de resíduos no entorno imediato do parque municipal do Mindu, acaba-se por notar que a interferência humana 
causa um desequilíbrio enorme para os ecossistemas inseridos na área protegida.

Uma das situações mais interessantes é o de uma floricultura instalada no setor oeste, quando a mesma utiliza a área do parque como depósito dos resíduos que, teoricamente, "são retirados semanalmente". Comumente alguns moradores do entorno ao reformarem suas residências têm um desagradável costume de destinar suas sobras de construção para o interior do parque municipal do Mindu, especificamente os moradores do setor oeste, repetidas vezes destinaram seus resíduos de forma irregular, apesar das orientações repassadas semanalmente pelos guardaparques, mostrou que para estas situações devem ser tomadas ações mais repreensivas. No ano de 2007, ações dirigidas por voluntários do parque e da Secretaria de limpeza pública diminuíram o volume de lixo deixado no interior da unidade de conservação, em específico no setor oeste e leste.

Quando do estabelecimento de uma unidade de conservação têm-se em mente, teoricamente, que esta área é uma região delimitada geograficamente livre de ações danosas à natureza, isto por que o ser humano é ciente de que a capacidade do meio ambiente de suportar as conseqüências de atividades impactantes é limitada.

No entanto o fato urbano, isto é, concentração humana nos espaços conhecidos como “Cidades”, traz inúmeros benefícios, mas outro número tão maior quanto, de malefícios.

A aglutinação de pessoas em espaços não concebidos para aglomerações humanas, desde séculos anteriores até o presente, causam inúmeras situações de risco à vida humana e de outros seres vivos. A Lei que institui a Política Nacional do Meio Ambiente n 6938/81 define, nas alíneas do inciso III do art. $3^{\circ}$ o que se deve entender por poluição, entendendo que todas as situações apontadas pela lei se enquadram com os lançamentos de resíduos destinados para o interior do parque municipal do Mindu.

Obras sem autorização: no levantamento realizado no parque municipal do Mindu, foram identificadas 18 obras sem autorização. Destaque ao limite Sul que possui ao lado de um estabelecimento comercial, dois poços artesianos perfurados no interior da unidade de conservação. Situações como estas deveriam ser combatidas, porém o apelo financeiro que estabelecimentos como estes aportam ao município é relativamente alto, no entender do judiciário local e, portanto, permanecem suas atividades utilizando recursos naturais de bem e uso comum de todos.

Partindo do pressuposto que todas as obras devem ser licenciadas por algum órgão fiscalizador, estes órgãos licenciadores consultariam oficialmente ou encaminhariam a gerência da unidade de conservação para proferir posicionamento sobre a avaliação de projeto ou obra com potencial poluidor, degradador ou utilizador de recurso natural, nos limites da zona de amortecimento da unidade de conservação, mesmo que a área protegida não possua plano de manejo como é o caso do Parque do Mindu, esta zona está identificada através de resolução do Conselho Nacional do Meio Ambiente de nº 13/90 até o estabelecimento do plano de manejo onde redefine os limites desta Zona para algo próximo a realidade do ecossistema protegido.

Catástrofes naturais ou nem tanto: representar espacialmente as catástrofes naturais do parque municipal do Mindu tornou-se um indicador extremamente eficaz para discernir se realmente eram catástrofes de origem natural ou catástrofes geradas pela falta de planejamento. Inicialmente pensou-se que todos os efeitos gerados por uma ação natural do ecossistema desencadearia um processo que propiciaria algum dano à unidade de conservação, porém no lançamento dos primeiros dados geográficos perceberam-se padrões que se repetiram ao longo de meses, principalmente àqueles referente as quedas de árvores.

Atualmente o parque municipal do Mindu, conta com um sistema de 12 trilhas e estas foram estabelecidas para a interpretação educativa voltada a conservação da natureza e outras para a fiscalização da área protegida. Das doze trilhas existentes apenas duas trilhas (da selva e da cachoeira), possuem o traçado apropriado à interpretação da natureza sem danificá-la, mas estas são pouco utilizadas, devido ao seu distanciamento da sede administrativa da unidade. 
As outras dez trilhas existentes foram replanejadas numa reforma em 2006 por equipe composta por técnicos da SEMMA e Construtora J. Nasser. Destas dez sofreram um aumento no corredor de passagem do tamanho de $1,25 \mathrm{~m}$ e $2,00 \mathrm{~m}$, considerado corredor equilibrado para a passagem de pessoas, FBPN (2006), para os atuais $4,00 \mathrm{~m}$ e até $8,00 \mathrm{~m}$, um corredor de passagem extremamente largo que propiciou à unidade de conservação um sério problema, conhecido como insularização ${ }^{5}$ interna.

Este aumento do "calibre" das trilhas fez com que as árvores estabelecidas às margens, que antes possuíam um desenho de caminho natural em área bosqueada conectadas por um dossel formado, fossem retiradas para abrir verdadeiras “avenidas” no interior do Parque, propiciando além da abertura do dossel formado, a inclinação das árvores dispostas ao longo das trilhas para obtenção de luz onde não mais existia conexão de dossel. Inclinações de plantas para obtenção de luz são típicas em árvores de bordas de fragmentos e não de árvores internas de fragmentos, como é o caso apresentado na unidade de conservação. Por isto nota-se um "ilhamento interno" do grande fragmento Parque do Mindu em pelo menos outros três fragmentos internos, estes propiciados pela abertura das trilhas demasiadamente largas.

Outro grande problema que causou um enorme prejuízo na perda de espécies florestais com porte arbóreo foi o traçado de três trilhas que não obedeciam às curvas de nível. Lechner e Caiut/CCCB (2004) propõem como restrições à implantação de trilhas: “Áreas frágeis como brejos e campos, áreas inadequada devido ao solo, com alta declividade e com possibilidade de enchentes”. Apontadas estas situações inadequadas para o estabelecimento das trilhas, implantou-se mesmo assim um traçado de trilhas que ao invés de acompanhar as curvas de nível, desenhou-se um traçado que corta as curvas de nível, expondo assim raízes de árvores de médio e grande porte, aumentando o fator de carreação de

\footnotetext{
5 Insularização: efeito secundário da fragmentação de um ecossistema que promove o isolamento de massas contínuas de floresta em esparsas “ilhas” isoladas do ecossistema original.
}

sedimentos e assoreando as poucas redes de drenagem existentes nas trilhas.

O corte das curvas de nível para abertura das trilhas, certamente propiciará em curto espaço de tempo a queda de todas as árvores com raízes expostas, como proposta de manejo e a fim de evitar qualquer acidente futuro, seria necessário tratos silviculturais e mesmo a remoção das árvores que possuem tendência elevada de queda.

As infra-estruturas que deveriam, teoricamente, contribuir com o uso-público na área protegida, exclusivamente no parque do Mindu, contribuíram para a aceleração da degradação da área. Um exemplo destas situações foi à instalação das infra-estruturas das trilhas que não são adequadas à região com alta incidência pluviométrica. A instalação de redes de drenagem em modelo quadricular $40 \mathrm{cmx} 40 \mathrm{~cm}$, não contribuiu para dispersar a velocidade das águas nas trilhas. Conciliado a isto, a inserção de escadas de concreto em solo podzólico, não apropriado para escoamento superficial, fez com que acelerassem os processos erosivos nas trilhas que possuíam estes tipos de estruturas cimentadas.

Contabilizando os fatos: para direcionar e concentrar esforços e recursos financeiros escassos resolveu-se contabilizar e setorizar os passivos ambientais do parque do Mindu, a fim de que medidas mitigadoras possam ser tomadas em curto espaço de tempo e dar uma forma mais cartesiana aos dados espaciais, a figura 2 bem como a figura 3, apresentam quali-quantitativamente qual o indicador com maior incidência na unidade de conservação e os setoriza a partir da informação geográfica.

Propostas que contribuam com a redução geral do maior indicador "lançamento de resíduos" no parque deveriam abarcar ações em nível de bacia hidrográfica, pois os limites leste, norte e sul sofrem influência direta do regime hídrico do igarapé do Mindu. Ações educativas ambientais e principalmente sanitárias contribuiriam na diminuição dos resíduos nestes setores. No entanto o limite oeste, o mais crítico, deveria sofrer intervenção de grande escala, pois são lançamentos de resíduos gerados pelos moradores do entorno imediato do parque (Indústrias, Comércios e Residências).

Rogério Fonseca et al.. 
Figura 2. Indicadores de passivos ambientais dispostos por setor, no parque do Mindu

Figure 2. Pointers of ambient liabilities made use by sector, in the Mindu Park

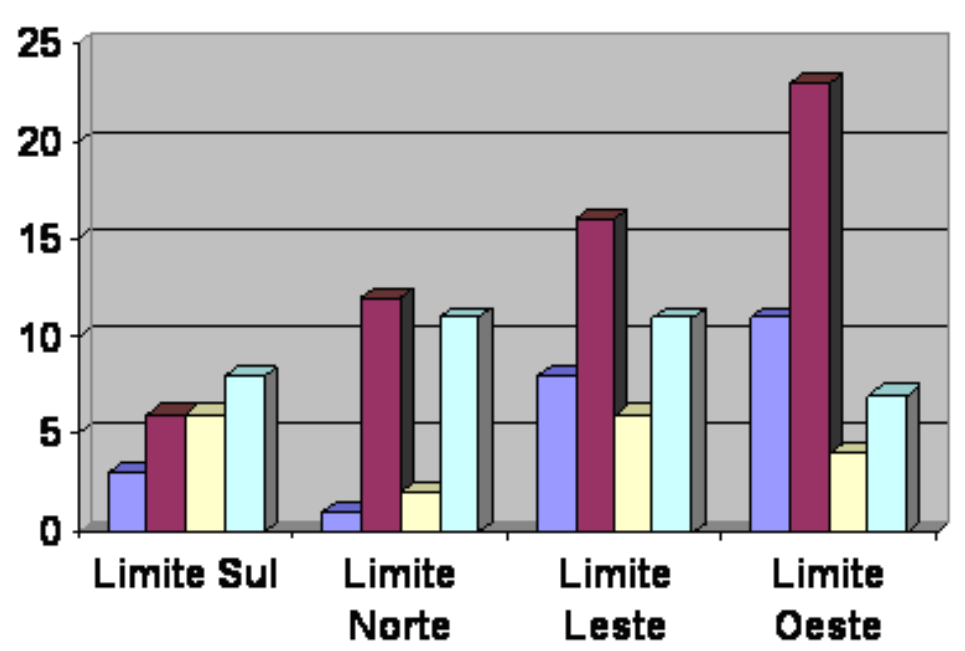

$\begin{aligned} & \text { Invasão de } \\ & \text { limites }\end{aligned}$
$\square$ Lançamento de
residuos
$\square$ Obras sem
autorização
$\square$ Catástrofes
naturais

Figura 3. Espacialização geral dos passivos ambientais do parque do Mindu.

Figure 3. General map of the ambient liabilities in the Mindu Park

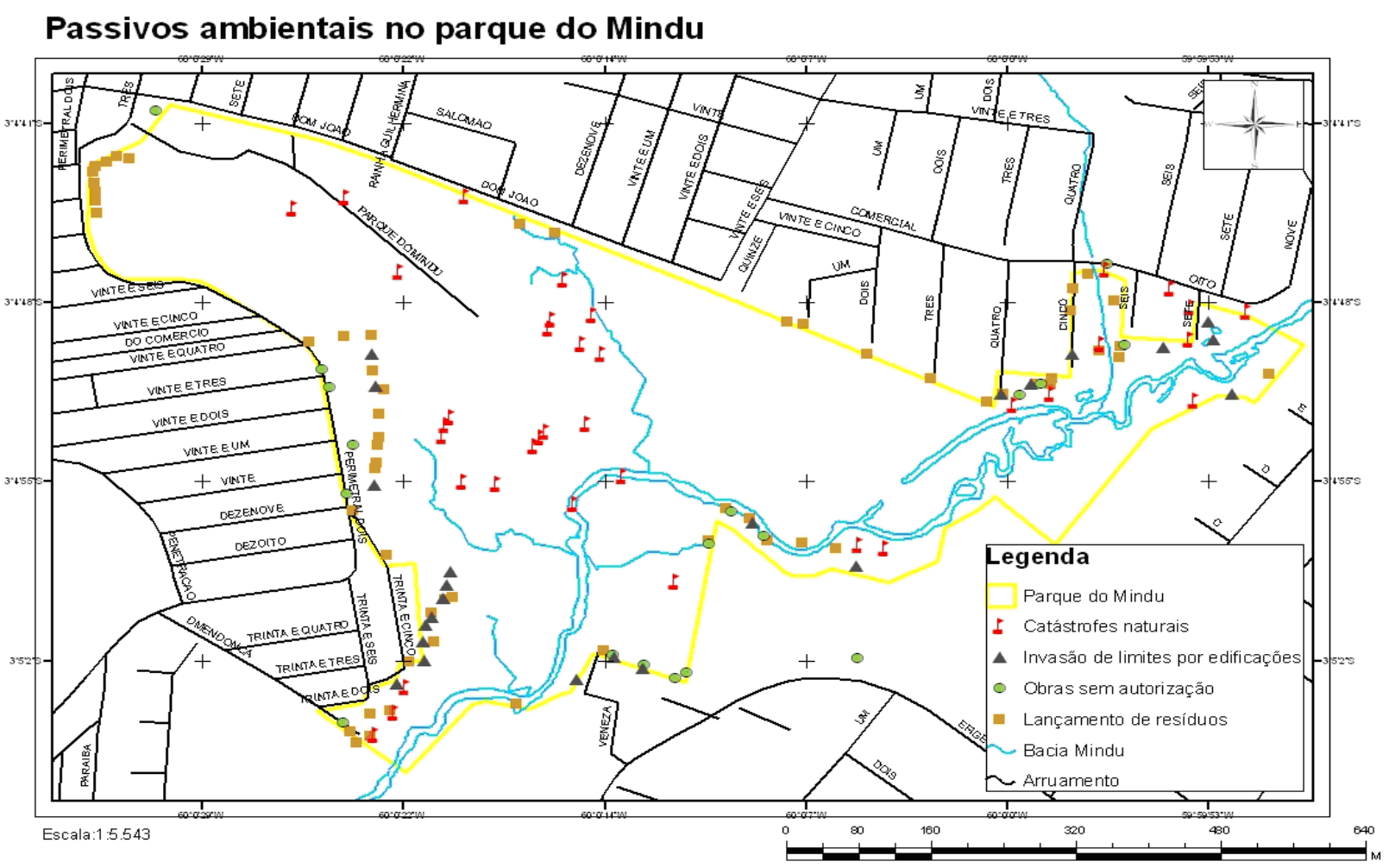


Quanto ao indicador "catástrofe natural”, a situação poderá se estabilizar após cinco anos, caso sejam tomadas em curto espaço de tempo, os tratos silviculturais cabíveis às árvores das trilhas, e tratos de engenharia de geologia nas infra-estruturas destas trilhas que possuam sulcos erosivos e redes de drenagem extremamente mal dimensionadas. No que se refere aos indicadores "obras sem autorização" e "invasão de limites”, jamais situações como estas deveriam ser admitidas pelo executivo local. O legislativo e judiciário, todavia, devem contribuir efetivamente para a consolidação da política ambiental brasileira a fim de que a unidade de conservação seja perpetuada para as futuras gerações.

\section{CONCLUSÃO}

Com o mapeamento dos “problemas” em uma área protegida de zona urbana consegue-se, em curto espaço de tempo, dinamizar a ação de equipes de defesa ambiental. O que se notava quando antes da compilação das ocorrências do Parque, era um grupo de pessoas que atuava em prol de descobrir algumas ocorrências na U.C., e não de uma equipe que sabia onde estava o problema que mais interferia na dinâmica geral da área protegida. O mapeamento dos passivos ambientais redirecionou as ações de manejo nas situações mais necessitadas da U.C. e permitiu que a equipe de gestão conduzisse autonomamente a inserção dos dados para a análise e solução dos problemas, objetivo este completamente atingido pelo Gestor do Parque, trabalhar de forma simples e barata, aperfeiçoando os recursos humanos e materiais.
Após o contínuo uso do mapeamento dos passivos ambientais, atualizados em tempo real, a ferramenta mostrou-se robusta para auxiliar na tomada de decisão principalmente no que tange a distribuição espacial das equipes na U.C., porém deve-se ressaltar que o lançamento dos dados para gerar estas informações só foi possível no desktop pessoal do gestor da unidade. Isto se deve ao simples fato de que a utilização de softwares livres dependia de anuência de setor específico da Prefeitura de Manaus, já que a mesma havia consolidado a licença de uso de outro software exclusivamente comercial, sendo este aspecto um fator extremamente limitante a gestão da unidade de conservação através de ferramentas geotecnológicas livres.

\section{AGRADECIMENTOS}

Ao CNPq, pelo apoio financeiro para executar pesquisa científica em nosso País.

\section{REFERÊNCIAS BIBLIOGRÁFICAS}

ARAÚJO, Marcos Antonio Reis. Unidades de Conservação no Brasil: da república à gestão de classe mundial. Belo Horizonte: DEGRAC, 2007.

CCCB, Centro de Capacitação em Conservação da Biodiversidade. Curso de Planejamento e Manejo de Áreas Naturais Protegidas - Fundação O Boticário de Proteção à Natureza. Guaraqueçaba, 2004.

FUNDAÇÃO O BOTICÁRIO DE PROTEÇÃO À NATUREZA (FBPN); Planejamento, implantação e manejo de trilhas em Unidades de Conservação - Larry Lechner. Cadernos de Conservação, ano 3, nº 3, Curitiba, 2006. 
GREGGIO, Thiago Claudino; PISSARRA, Teresa Cristina Tarlé e RODRIGUES, Flávia Mazzer. Avaliação dos fragmentos florestais do município de Jaboticabal-SP. Rev. Árvore [online]. 2009, vol.33, n.1.

MANAUS, Diário Oficial do Município de, 21 de maio de 2007, Decreto nº. 9043 de redelimitação e ampliação do Parque Municipal do Mindu, Manaus, Amazonas

PINHEIRO JUNIOR, José de Ribamar, Uso de geotecnologias como subsídios à gestão do Parque Estadual do Bacanga, São Luis, Maranhão, Brasil, Dissertação de mestrado, Universidade Federal do Amazonas, Manaus, 2006.

SILVA, Jorge Xavier da. Geoprocessamento e Análise Ambiental: aplicações, Jorge Xavier da Silva, Ricardo Tavares Zaidan (Organizadores), Rio de Janeiro: Bertrand Brasil, 2007. 